\title{
Prediction of Rust Thickness in Reinforced Concrete Structures to Enhance the Asset Management for Coastal Infrastructures
}

\author{
Wahyuniarsih Sutrisno ${ }^{1, \mathrm{a})}$, I Ketut Hartana ${ }^{1, \mathrm{~b})}$ \& Priyo Suprobo ${ }^{1, \mathrm{c})}$ \\ ${ }^{1)}$ Department of Civil Engineering, Institut Teknologi Sepuluh Nopember (ITS), Surabaya, Indonesia. \\ Correspondent : $\left.{ }^{a}\right)$ niar1206@gmail.com, $\left.{ }^{b}\right)$ har3110@gmail.com \& ${ }^{c}$ priyo@ce.its.ac.id
}

\begin{abstract}
Corrosion in reinforced concrete structure is a serious problem, especially for coastal infrastructure. Managing the coastal infrastructure from corrosion is a really essential action, to make sure that the infrastructure can be used properly throughout its service live. This research focused on analyzing the rust thickness on steel reinforcement due to corrosion. Series of corrosion test using galvanostatic was performed in this research. Furthermore, a predictive model based on Farraday's Law with uniform corrosion assumption also developed in this research and compared with the experimental data. Based on the simulation result, it was found that the predictive model of rust thickness based on Farraday's Law is capable to simulate the corrosion process and thickness of the rust.
\end{abstract}

Keyword: infrastructure management, coastal infrastructure, reinforced concrete structure, corrosion, uniform rust thickness.

\section{INTRODUCTION}

Coastal infrastructure is one of the most important aspects of human living in the coastal region. Managing the coastal infrastructures such as bridges and harbor is quite challenging due to its location and environmental characteristics (Almeida \& Mostafavi, 2016; Straub, Malioka, \& Faber, 2009; Valdez et al., 2016). Furthermore, the coastal area, including onshore and offshore area, has different characteristics and effect to the infrastructures. Up until now, concrete still becomes the main choice of the practitioner due to its benefit such as strength, rigidity, and resilience from deformation. However, the characteristics of concrete causes concrete have lower tensile stress compared to steel. Cracking of a reinforced concrete structure is one indication of structural failure. Nevertheless, it is a large chance that deterioration has occurred before the cracks appear. Cracking can happen in both fresh and hardened concrete as a result of volume changes and repeated loading. In hardened concrete, cracking can be caused by different mechanisms such as drying shrinkage, poor construction performances, loading, weather condition, thermal stresses, chemical reactions, and the corrosion of steel reinforcing.

As mentioned in Basic Principle of Infrastructure Asset Management (IAM), maintenance is a vital work of IAM, to ensure a good infrastructure physical condition. While maintenance system is organized mainly based on typical infrastructure damage (Suprayitno \& Soemitro 2018). Therefore, understanding the rust thickness prediction for reinforced concrete structure in coastal environment is crucial.

As for durability problems, concrete known has a lot of capillary pores and air voids that can influence the concrete permeability to a larger extent. This condition makes concrete really susceptible to durability problems such as corrosion. The corrosion process in reinforced concrete is a complex problem which includes three main stages which are 
initiation stage, corrosion development stage, and corrosion induced cracking stage. The corrosion development stage is a very important stage because at this time the rust expands and eventually cause cracking into the concrete (Zhao, Ren, Dai, \& Jin, 2011; Zhao, Yu, Hu, \& Jin, 2012; Zhao, Yu, Wu, \& Jin, 2012). Corrosion in concrete can influence the bond behavior of concrete structure which plays an important role in the overall behavior of concrete (Zhu, Dai, \& Poon, 2018). The field investigation regarding crack to the concrete shows that the most concerning problems related to the corrosion were cracking and spalling of the concrete cover. If this problem not handled properly, it can lead to permanent failure of the structural (Cao, Cheung, \& Chan, 2013; Li \& Wang, 2008). Therefore, it is very important to predict the rust thickness in order to predict the damage of concrete due to corrosion. This research focused on analyzing and predicting the rust thickness in concrete steel reinforcement due to corrosion. The infamous Faraday's Law will be used as the basic formulation to calculate the uniform rust thickness.

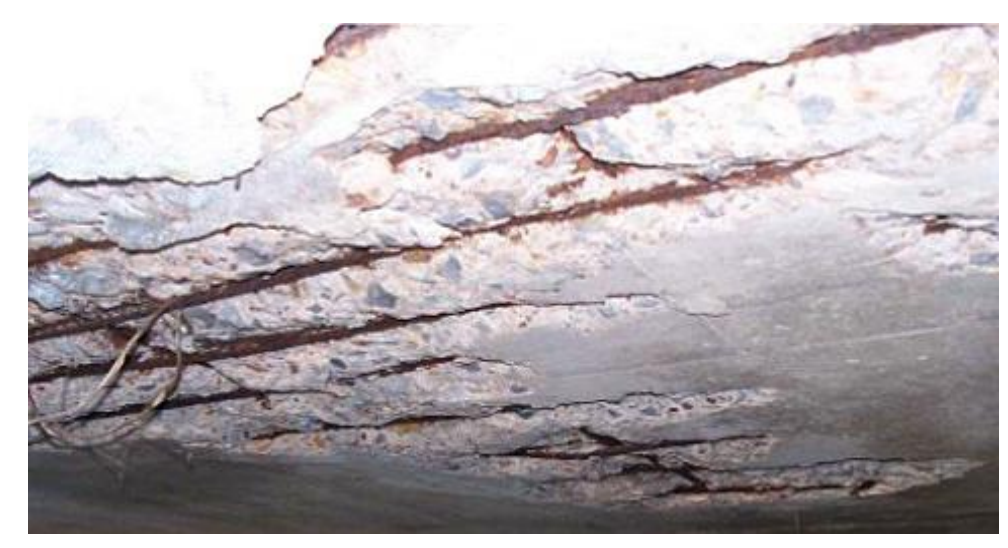

Figure 1. Corrosion in Reinforced Concrete Slab of JettyStructure

\section{CORROSION INDUCED CRACKING OF REINFORCED CONCRETE STUCTURES}

The corrosion process in reinforced concrete structure is an electrochemical process between water, metal, and oxygen. Moreover, concrete is heteregenous materials which have a lot of pores which make water and oxygen can infiltrate into the concrete. In an aggressive environment such as marine environment, the water which infiltrates into the concrete can contain aggressive ions such as chloride, sulphate, etc. This ion can accelerate the corrosion process and eventually induced damage to the structure.

Damage in a reinforced concrete structure is often associated with the appearance of crack. In fact, the crack in concrete is a very common condition. Almost every concrete structure has a crack which can occur due to different causes such as loading, shrinkage, creep, etc. In reinforced concrete, corrosion is a major cause of durability problem which can lead to overall damage to the structures (Chen \& Mahadevan, 2008). In case of corrosion due to chloride infiltration, the chloride ions from aggresive environment act as a catalyst which can accelerate the rust formation. Reinforced concrete in aggressive environments, such as marine environments is very susceptible to corrosion due to sea water. Sea water actually containing aggressive ions which can accelerate the corrosion of reinforced concrete structures. The chloride induced corrosion process illustrated in Figure 1. 


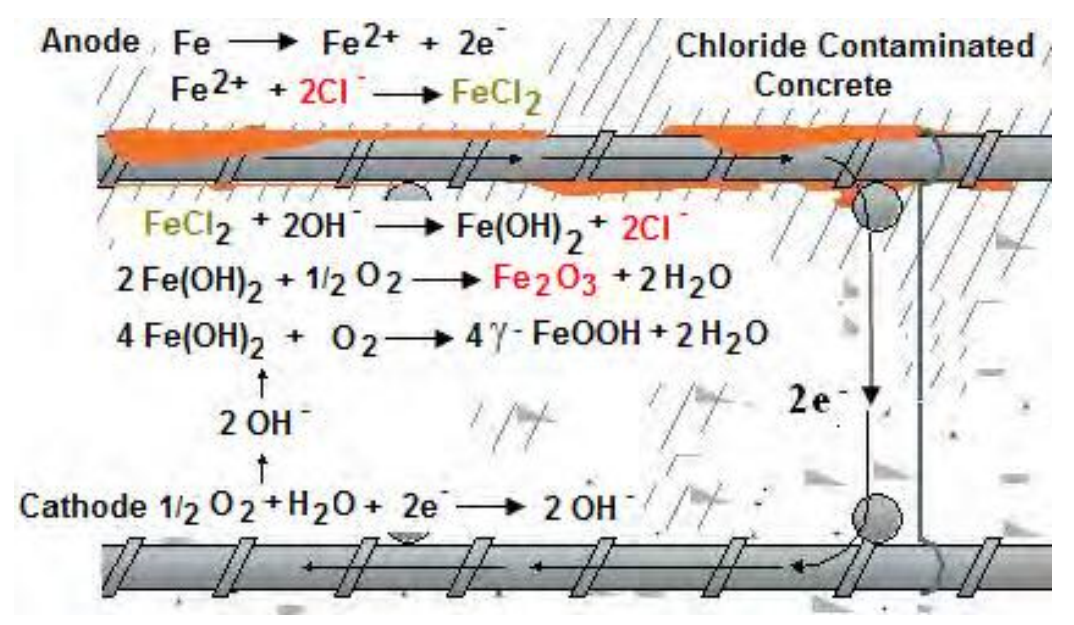

Figure 2. Corrosion Process Induced by Chloride Infiltration (Shi, Xie, Fortune, \& Gong, 2012)

After the passive layer between concrete and steel bar start to damage, the corrosion starts to occur. The corrosion will continue to expand as long as the concentration of $\mathrm{H}_{2} \mathrm{O}$ and $\mathrm{O}_{2}$ in concrete still sufficient. Over time the stress due to rust expansion can exceed the tensile stress of concrete and initiate the crack formation. After some time, a crack in the concrete can propagate into the concrete surface and eventually cause damage to the structure. The scheme of the crack due to corrosion is shown in Figure 2. Moreover, corrosion also can damage the bond between concrete and concrete. This condition very undesirable because concrete has a very low tensile capacity and this condition can cause failure to the structures.

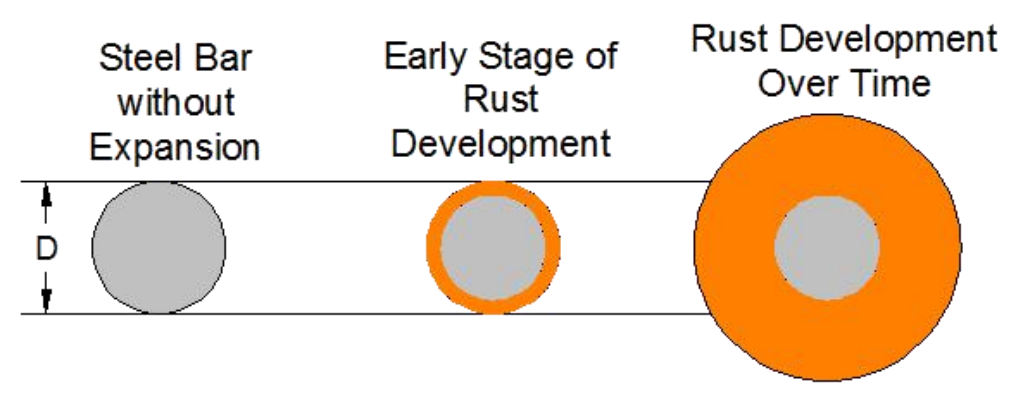

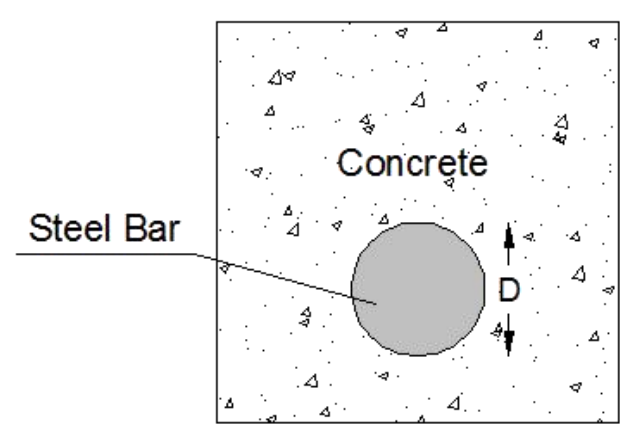

Before Corrosion

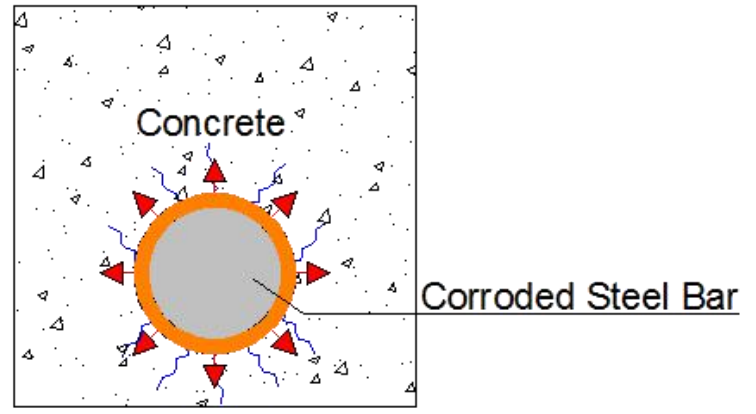

After Corrosion

Figure 3. Damage Process of Concrete due to Corrosion (Sutrisno, Suprobo, Wahyuni, \& Iranata, 2017)

\section{PREDICTIVE MODEL OF THE RUST THICKNESS OF STEEL REINFORCEMENT}

The Faraday's law has been often used to simulate the general corrosion in steel or another metal product. By using this law, the calculation of corrosion rate which corresponding to mass loss due to corrosion can be performed. By using faradays law, the 
theorethical mass of corrosion product $\left(\mathrm{M}_{\mathrm{th}}\right)$ per unit is at a specific time and known the applied current is expressed as follow (Ahmad, 2009):

$$
M_{t h}=\frac{W I_{a p p} T}{F}
$$

Where; $\mathrm{T}$ is the exposed time; $\mathrm{I}_{\text {app }}$ is the applied current density $\left(\mathrm{Amp} / \mathrm{cm}^{2}\right) ; \mathrm{W}$ is the equivalent weight of steel (gr) and F is Faraday's constant (Amp-sec). Based on the Faraday's Law, the actual mass of the corrosion product should be represented by the theoretical mass which calculated using Eq 2. The actual mass of the corrosion product $\left(\mathrm{M}_{\mathrm{ac}}\right)$ can be obtained by conducting the gravimetric test with the procedure is shown in ASTM G1. The theoretical mass can be calculated using Equation below:

$$
M_{a c}=\frac{W_{i}-W_{f}}{\pi D L}
$$

The $\mathrm{W}_{\mathrm{i}}$ and $\mathrm{W}_{\mathrm{f}}$ indicate the weight of steel reinforcement before and after corrosion respectively (gr). While D is the steel reinforcement diameter $(\mathrm{cm})$ and $\mathrm{L}$ is the length of the steel reinforcement $(\mathrm{cm})$. The reduction value of $\mathrm{Wi}$ and $\mathrm{Wf}$ represent the weight of the rust due to the corrosion process. By using equation 3, the actual degree of corrosion degree can be calculated in terms of the weight loss percentage $(\rho)$ as follow:

$$
\rho=\frac{\left(W_{i}-W_{f}\right)}{W_{i}} \times 100
$$

Taking account that the actual mass of the rust is equivalent with the theoretical mass which calculated using Farraday's Law, the equivalent corrosion current density, $I_{\text {corr, }}$ can be expressed as below:

$$
I_{\text {corr }}=\frac{\left(W_{i}-W_{f}\right) F}{\pi D L W T}
$$

Thus the weight of the rust can be written as:

$$
\left(W_{i}-W_{f}\right)=\frac{I_{c o r r} \pi D L W T}{F}
$$

By substitutes the equation (5) to the equation (3) the percentage of corrosion can be written as:

$$
\rho=\frac{I_{c o r r} \pi D L W T}{F W_{i}} \times 100
$$

For simplicity, the corrosion product is assumed to spread uniformly along the surface of the steel reinforcement. By using two dimensional analysis along the cross section of the steel reinforcement, the area of the corrosion product along the circumference of the steel bar (Ar) can be calculated using the equation below:

$$
A_{r}=\rho A_{s} n
$$


$\mathrm{A}_{\mathrm{s}}$ is the un-corroded steel reinforcement cross section area and $\mathrm{n}$ is volume expansion ratio of corrosion product. By using equation 8 the uniform thickness of the reinforcement can be calculated by deviding the area of the corrosion product with the circumference of the steel bar as follows:

$$
U_{n}=\frac{A_{r}}{\pi D}
$$

\section{THE EXPERIMENTAL TEST OF CORROSION INDUCED CRACK}

The experimental test was performed by using the galvanostatic method. Specimens used for the specimen is reinforced concrete with $150 \times 150 \times 150 \mathrm{~mm}$ dimension with $19 \mathrm{~mm}$ single deformed steel reinforcement wich placed $40 \mathrm{~mm}$ from the exposed surface. The concrete used for this experimental test is normal concrete with compressive strength $30 \mathrm{MPa}$. The corrosion process was generated by using constant corrosion current density of approximately $190 \mu \mathrm{A} / \mathrm{cm}^{2}$ and $5 \% \mathrm{NaCl}$ solution. The illustration of the corrosion process shows in Figure 3. The accelerated corrosion process was performed by using a constant electrical current to the steel reinforcement by a DC power supply. In this experiment, the steel plate submerged in the $\mathrm{NaCl}$ solution and acts as the cathode. Furthermore, the steel reinforcement acts as an anode and the concrete's pore fluid acts as the electrolyte.

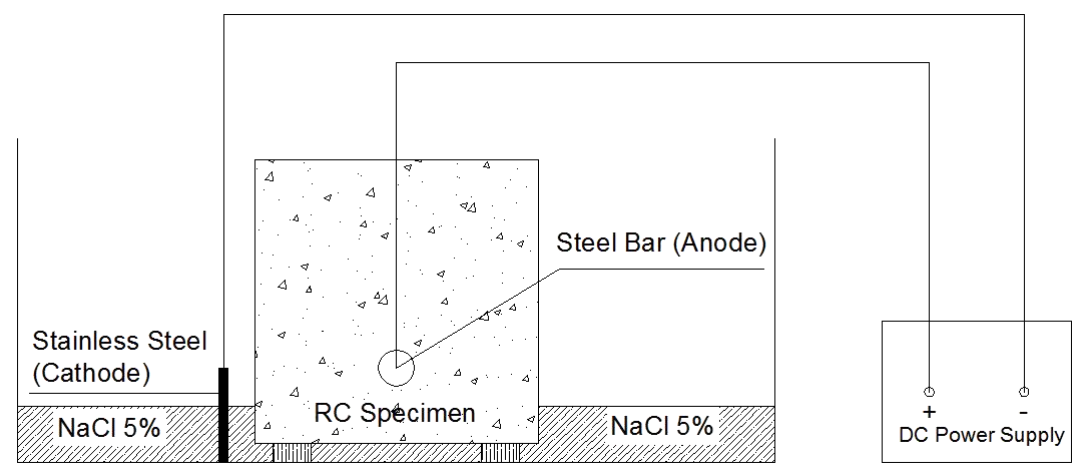

Figure 4. Accelerated Corrosion Test Set Up

To observe the thickness of the corrosion product, the concrete sample was prudently sliced into four identical pieces as shown in Figure 5. The rust thickness was observed by using a hand microscope and digital image processing. The thickness of the rust than plotted according to the polar coordinate system shows the rust distribution of the sample.

\section{Sliced Specimen}

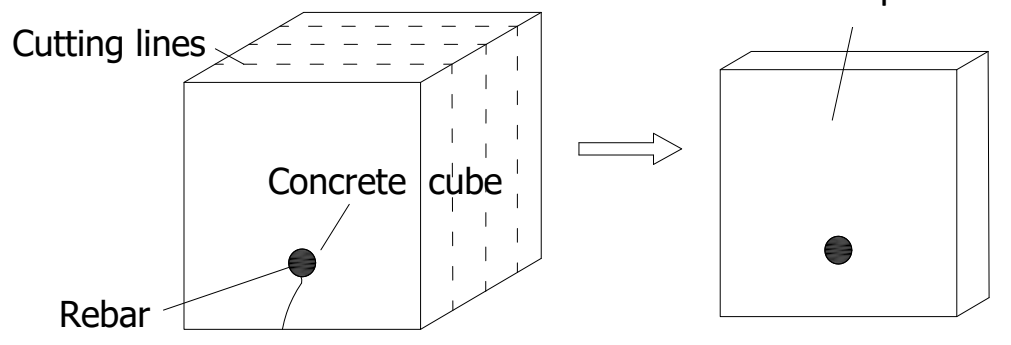

Figure 5. Cutting Scheme for the Rust Observation

\section{RESULT AND DISCUSSION}

Series of the experimental test was performed in this study to investigate the rust thickness in concrete reinforcing steel. The daily observation was conducted to observe the 
corrosion development over time. To observe the rust thickness and distribution at the cross section sample, the concrete was cut into four identical pieces. The thickness of the rust around the circumference of the steel bars was described in terms of a polar coordinate. Figure 4 shows the corrosion of the sample after the corrosion test and cutting.

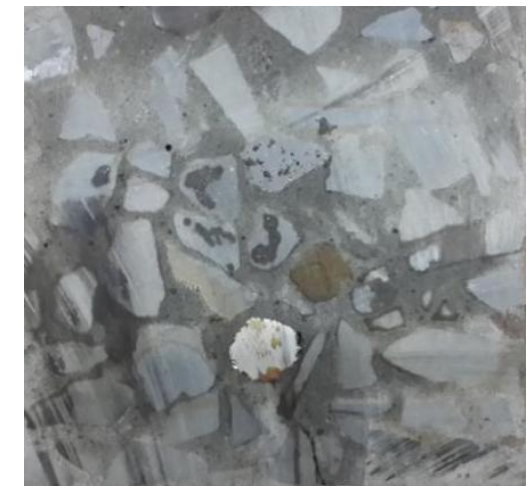

Part 1

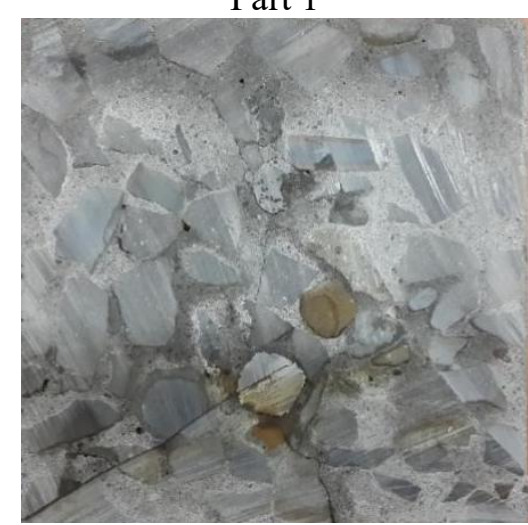

Part 3

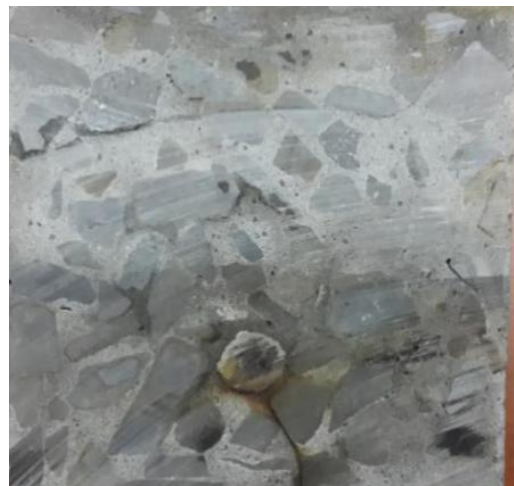

Part 2

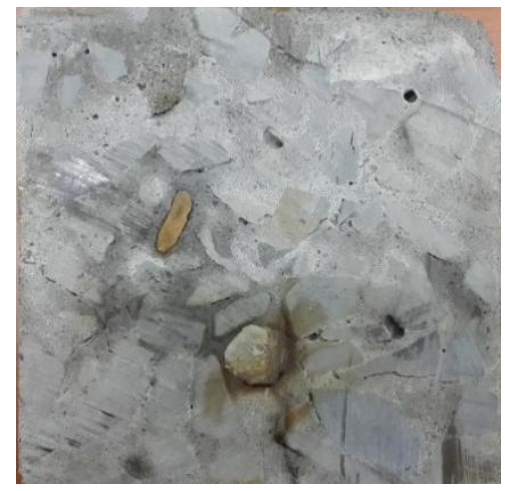

Part 4

Figure 6. Concrete Condition after Slicing

After cutting the sample the rust thickness of each sample was observed. Furthermore, the weight of the corroded steel bar also measured after cleaning the rust on the stell bar surface. Table 1 shows the actual weight loss observation result. The table shows that the production of rust mass highly depends on the time of exposure. As the time of exposure increase, the mass of the rust due to corrosion process also increased.

Table 1. Actual Weight Loss

\begin{tabular}{|c|c|c|c|}
\hline Exposure Time & Initial Weight (Wi) & Weight After Corrosion (Wf) & Actual Weight Loss \\
\hline (Days) & $\mathbf{( G r )}$ & $(\mathbf{G r})$ & $\mathbf{( G r )}$ \\
\hline 4 & 566.588 & 557.125 & 9.463 \\
\hline 6 & 566.595 & 552.125 & 14.470 \\
\hline 10 & 566.593 & 542.224 & 24.369 \\
\hline 15 & 566.589 & 530.191 & 36.398 \\
\hline 20 & 566.594 & 518.622 & 47.972 \\
\hline
\end{tabular}

The rust thickness was observed by using a hand microscope and digital image processing. Figure 7 below shows the actual and analytical model of rust distribution due to corrosion over time. It can be seen that the actual distribution of rust happened in a nonuniform manner. The area closest to the surface produces more rust compared with another 
area due to the availability of water and oxygen. For the area closest to the surface, the flow of the water and oxygen into the concrete is quicker than other areas. As it is well known that corrosion in reinforced concrete happen due to the reaction between steel, pores water and oxygen in the concrete, more flow at the area near to exposed surface has higher chance to suffer from corrosion.

The predictive model discussed in the previous section was used to calculate the rust thickness over time for each sample. As the uniform corrosion approach was used for the predictive model, the rust thickness at the area far from exposed surface shows noticeable differences. However, for the area near from exposed surface, the rust thickness shows almost similar peak value. Therefore, for the future study, it needs to make more accurate rust thickness model to enhance the accuracy of the rust distribution.

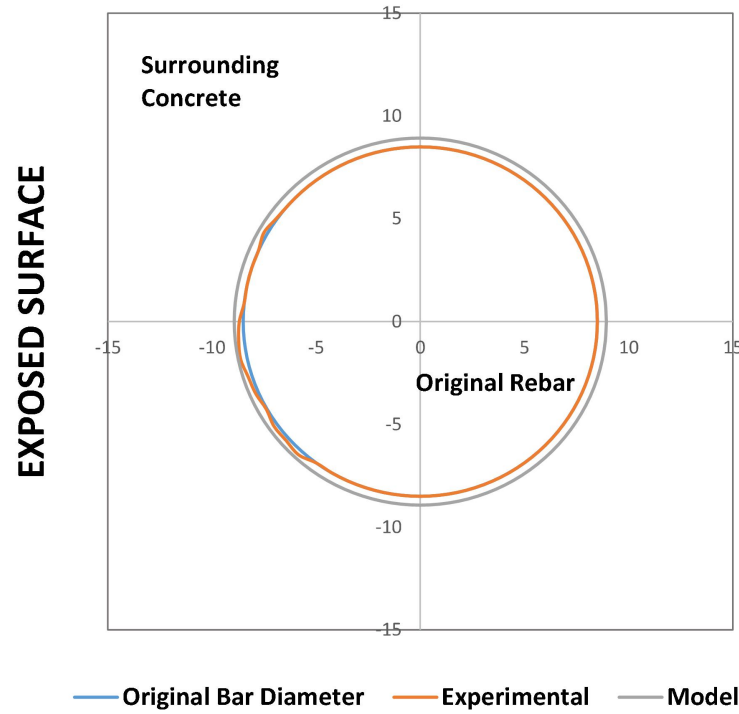

Day 4

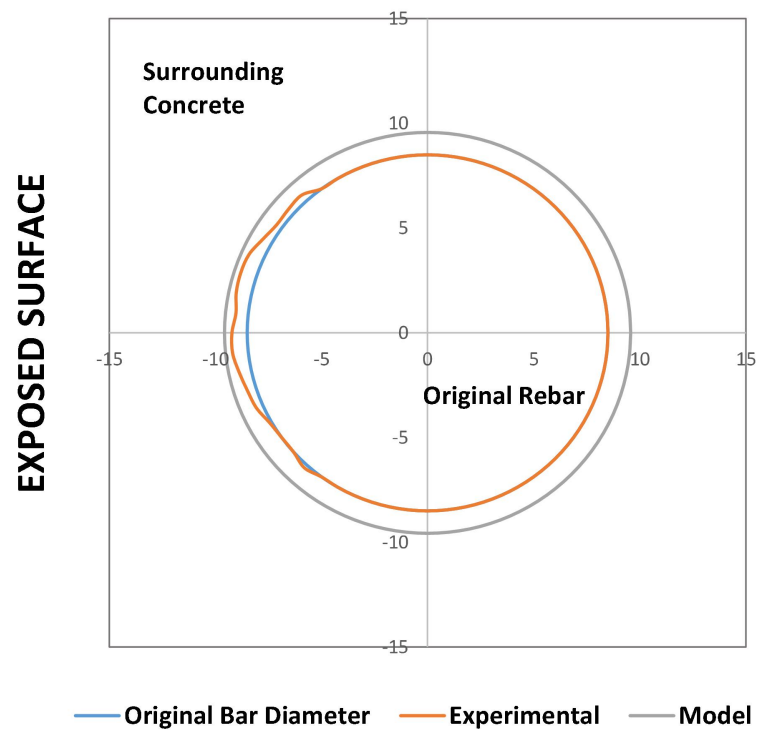

Day 10

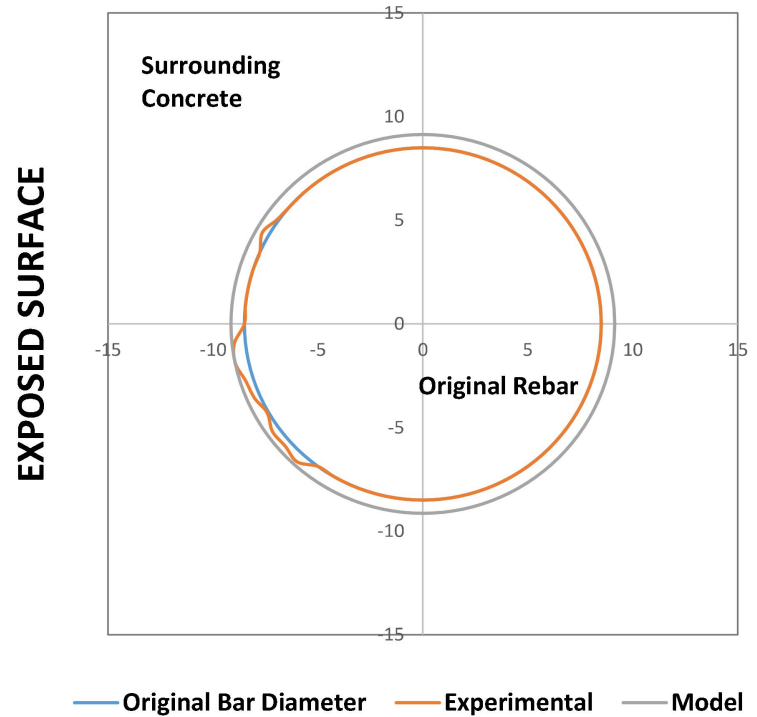

Day 6

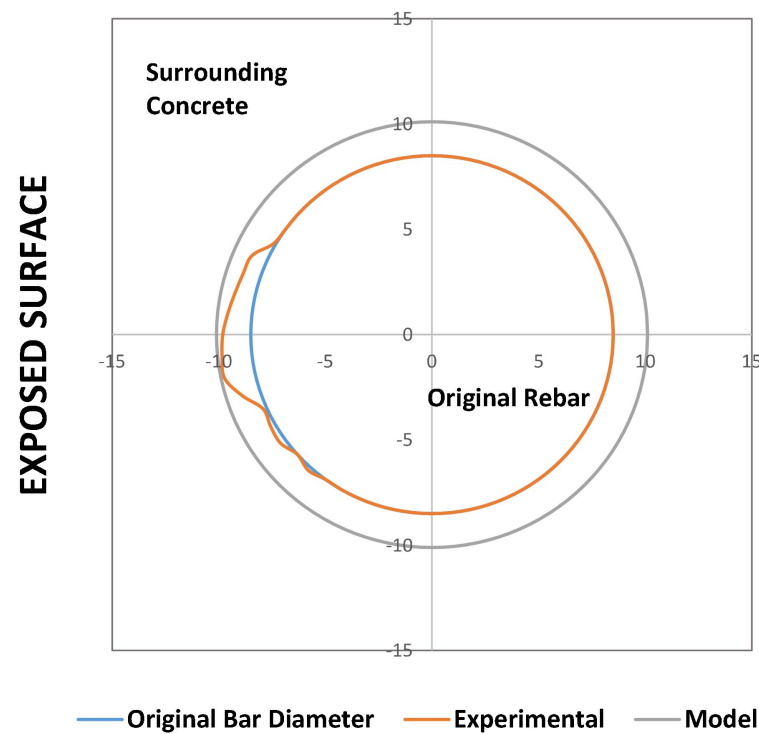

Day 15 


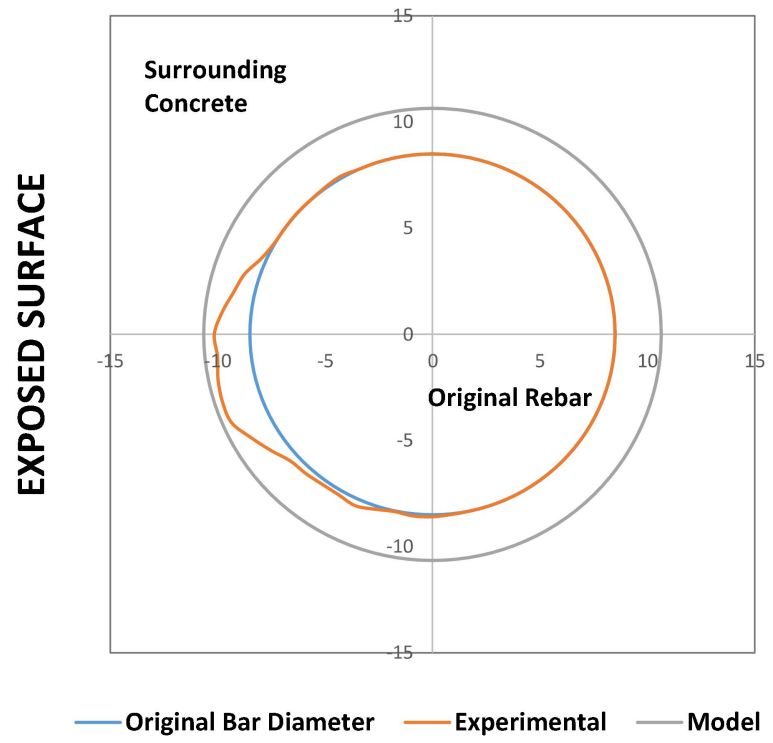

Day 20

Figure 7. Actual and Theoretical (Model) Rust Thickness Distribution (mm)

\section{CONCLUSION}

A predictive model of corrosion induced cracking has been developed based on Faraday's law. The model was developed by using a uniform corrosion assumption. To verify the model, an accelerated corrosion test was performed to a normal reinforced concrete cube sample. The analysis result shows that the uniform corrosion model has similar peak of rust thickness compared with the experimental result. The peak of the rust occurs at the area near the exposed surface. However, the experimental result shows that the rust distributed in a nonuniform pattern. Hence, for the area far from the exposed surface, a noticeable difference of rust thickness can be seen. Therefore, it is important to take the non-uniform factor of the rust distribution to produce a more accurate prediction of rust thickness.

\section{BIBLIOGRAPHY}

Ahmad, S. (2009). "Techniques for Inducing Accelerated Corrosion of Steel In Concrete". The Arabian Journal for Science and Tecchnology, 34(2), 95-104.

Almeida, B. A. De, \& Mostafavi, A. (2016). "Resilience of Infrastructure Systems to SeaLevel Rise in Coastal Areas: Impacts , Adaptation Measures, and Implementation Challenges". Sustainability, 8. http://doi.org/10.3390/su8111115

Cao, C., Cheung, M. M. S., \& Chan, B. Y. B. (2013). "Modelling Of Interaction Between Corrosion-Induced Concrete Cover Crack And Steel Corrosion Rate". Corrosion Science, 69(24), 97-109. http://doi.org/10.1016/j.corsci.2012.11.028.

Chen, D., \& Mahadevan, S. (2008). "Chloride-Induced Reinforcement Corrosion And Concrete Cracking Simulation". Cement and Concrete Composites, 30(3), 227-238. http://doi.org/10.1016/j.cemconcomp.2006.10.007

Li, S., \& Wang, M. (2008). "Model For Cover Cracking Due To Corrosion Expansion And Uniform Stresses At Infinity". Applied Mathematical Modelling, 32, 1436-1444. http://doi.org/10.1016/j.apm.2007.06.003

Shi, X., Xie, N., Fortune, K., \& Gong, J. (2012). "Durability Of Steel Reinforced Concrete In Chloride Environments: An Overview". Construction and Building Materials, 30, 125138. http://doi.org/10.1016/j.conbuildmat.2011.12.038 
Straub, D., Malioka, V., \& Faber, M. H. (2009). "Structure And Infrastructure Engineering: Maintenance, Management, Life-Cycle Design And Performance A Framework For The Asset Integrity Management Of Large Deteriorating Concrete Structures". Structure and Infrastructure Engineering, 5(3), 199-213. http://doi.org/10.1080/15732470601017369

Suprayitno, H. \& Soemitro, R.A.A. (2018). "Preliminary Reflexion on Basic Principle of Infrastructure Asset Management". Jurnal Manajemen Aset Infrastruktur \& Fasilitas, 2(1), Maret 2018.

Sutrisno, W., Suprobo, P., Wahyuni, E., \& Iranata, D. (2017). "Investigation of Non-Uniform Rust Distribution and its Effects on Corrosion Induced Cracking in Reinforced Concrete”. In Matec Web Conference (pp. 1-10). http://doi.org/10.1051/matecconf/ 201713802013

Valdez, B., Ramirez, J., Eliezer, A., Schorr, M., Ramos, R., \& Salinas, R. (2016). "Corrosion Assessment of Infrastructure Assets in Coastal Seas". Journal of Marine Engineering and Technology, 15(3), 124-134. http://doi.org/10.1080/20464177.2016.1247635

Zhao, Y., Ren, H., Dai, H., \& Jin, W. (2011). "Composition And Expansion Coefficient of Rust Based on X-Ray Diffraction and Thermal Analysis". Corrosion Science, 53(5), 1646-1658. http://doi.org/10.1016/j.corsci.2011.01.007

Zhao, Y., Yu, J., Hu, B., \& Jin, W. (2012). "Crack Shape And Rust Distribution In CorrosionInduced Cracking Concrete". Corrosion Science, 55, 385-393. http://doi.org/10.1016/j.corsci.2011.11.002

Zhao, Y., Yu, J., Wu, Y., \& Jin, W. (2012). "Critical Thickness of Rust Layer At Inner And Out Surface Cracking of Concrete Cover In Reinforced Concrete Structures". Corrosion Science, 59, 316-323. http://doi.org/10.1016/j.corsci.2012.03.018

Zhu, W., Dai, J., \& Poon, C. (2018). "Prediction of The Bond Strength Between NonUniformly Corroded Steel Reinforcement and Deteriorated Concrete". Construction and Building Materials, 187, 1267-1276. http://doi.org/10.1016/j.conbuildmat.2018.07.139 
(e)ISSN 2656-8896 (p)ISSN 2656-890X

Journal of Infrastructure and Facility Asset Management - Vol. 1, Issue. 2, September 2019 